\begin{abstract}
Iranica
Abstracta Iranica Revue bibliographique pour le domaine irano-aryen

Volume 34-35-36 | 2017

Comptes rendus des publications de 2011-2013
\end{abstract}

\title{
Barbara Kaim. Serakhs Oasis at the Crossroads of Communication Routes
}

\section{Rémy Boucharlat}

\section{(2) OpenEdition}

1 Journals

\section{Édition électronique}

URL : http://journals.openedition.org/abstractairanica/42070

DOI : 10.4000/abstractairanica.42070

ISSN : 1961-960X

Éditeur :

CNRS (UMR 7528 Mondes iraniens et indiens), Éditions de l'IFRI

\section{Référence électronique}

Rémy Boucharlat, "Barbara Kaim. Serakhs Oasis at the Crossroads of Communication Routes », Abstracta Iranica [En ligne], Volume 34-35-36 | 2017, document 10, mis en ligne le 30 juillet 2017, consulté le 26 septembre 2020. URL : http://journals.openedition.org/abstractairanica/42070 ; DOI : https://doi.org/10.4000/abstractairanica.42070

Ce document a été généré automatiquement le 26 septembre 2020.

Tous droits réservés 


\title{
Barbara Kaim. Serakhs Oasis at the Crossroads of Communication Routes
}

\author{
Rémy Boucharlat
}

\section{RÉFÉRENCE}

Barbara Kaim. « Serakhs Oasis at the Crossroads of Communication Routes ». Parthica 14 (Essays in Memory of Boris Anatol'evich Litvinsky), 2012 [2013], p. 149-159.

1 L'oasis de Serakhs, situé dans le delta de la rivère Tedjen, à l'extrême angle NE de l'Iran chevauche la frontière Iran-Turkménistan. Du côté de ce dernier pays, les travaux des archéologues soviétiques des années 50 et 60 du siècle dernier avaient montré que l'oasis avait été peuplée du $\mathrm{I}^{\mathrm{er}}$ mill. av. J.-C. jusqu'en 1832. Une équipe archéologique polono-turkmène y a travaillé pendant dix ans, principalement sur un temple du feu, nommé Mele Hairam, en activité du $\mathrm{I}^{\mathrm{er}}$ au $\mathrm{IV}^{\mathrm{e}} \mathrm{s}$. de n.è., selon les monnaies trouvées en fouilles, entre le Parthe Artaban II et le Sassanide Shapur II (voir les rapports de fouilles dans IA 37, 2002 et 39, 2004). L'A. présente ici des matériaux et objets de Mele Hairam qui, par sa situation géographique, entre l'Iran et l'Asie centrale, témoignent de relations à longue distance. En atteste un cylindre en lapis-lazuli, mais aussi des traces de pigment obtenu à partir de cette pierre semi-précieuse, comme l'ont révélé des analyses. Un autre pigment, le cinabre peut provenir soit du Turkestan russe ou du Yunan en Chine, soit de l'Iran du nord-ouest. Le corail et la nacre sont également d'origines lointaines, tandis que l'albâtre a été obtenu depuis le Kopet Dag, ce que montre les déchets de taille sur place. L'art montre également des relations très lointaines, l'influence ou une importation du monde kouchan (une plaque en ivoire et une statuette féminine), et même de Chine (un miroir en bronze). 


\section{AUTEURS}

\section{RÉMY BOUCHARLAT}

UMR 5133 CNRS-Université de Lyon 